\title{
Análise da Relação Entre a Taxa de Câmbio e os Desembarques Domésticos e Internacionais no Brasil
}

\author{
Daniela de Moura Pavão Farias \\ Lara Régia de Mélo Filho ${ }^{b}$ \\ Marcos Felipe Falcão Sobral \\ André de Souza Melo ${ }^{d}$
}

\section{Resumo}

Este artigo propõe-se analisar, através de um teste econométrico, os efeitos da taxa de câmbio nominal sobre o número de desembarques nacionais e internacionais aéreos, no Brasil, no período de 2001 a 2016. Como metodologia, utilizou-se o modelo de vetores autorregressivos. A análise dos resultados demonstra que há uma relação de causalidade e influência entre as variáveis. Observou-se que o câmbio influenciou as demais variáveis, mas não foi influenciado por elas. Além disso, o desembarque doméstico representou a variável que mais sofreu impactos da taxa de câmbio nominal e do desembarque internacional. Os achados da pesquisa corroboram com outros trabalhos que afirmam que a demanda turística é afetada pelo câmbio. No entanto, a inovação desse artigo consistiu em utilizar os desembarques tanto nacionais como internacionais como variáveis para analisar a possível interferência da taxa de câmbio nelas.

Palavras-chave: Taxa de câmbio nominal; Desembarques internacionais; Desembarques nacionais; Vetores autorregressivo.

\section{Abstract \\ Analysis of the Relationship between the Exchange Rate and Domestic and International Arrivals in Brazil}

This article aims to analyze, through an econometric test, the effects of the nominal exchange rate on the number of domestic and international tourist arrivals in Brazil from 2001 to 2016. The methodology was an exploratory and quantitative research with a secondary data, using vectors autoregression to identify Granger causality, decomposition of variance and impulse response function. The analysis shows that there is a relation of causality and influence between the variables. It was noted that the exchange rate assumed in this study, the role of the most independent variable, because it influenced the other variables, but was not influenced by them. In addition, the domestic arrivals

a. Mestre do Programa de Pós-Graduação em Administração e Desenvolvimento Rural pela Universidade Federal Rural de Pernambuco (UFRPE), Recife, Pernambuco, Brasil. E-mail: daniela. pavao@hotmail.com

b. Mestre do Programa de Pós-Graduação em Administração e Desenvolvimento Rural pela Universidade Federal Rural de Pernambuco (UFRPE). Docente de Técnico em Logística, Técnico em Informática para Internet, Tecnólogo em Gestão da Qualidade e Tecnólogo em Informática para Internet no Instituto Federal de Pernambuco (IFPE) e docente de Bacharelado em Administração no Centro Universitário Brasileiro (UNIBRA), Recife, Pernambuco, Brasil. E-mail: lararmf@gmail.com

c. Doutor em Engenharia da Produção pela Universidade Federal de Pernambuco (UFPE). Docente do Programa de Pós-graduação em Administração e Desenvolvimento Rural na Universidade Federal Rural de Pernambuco (UFRPE), Recife, Pernambuco, Brasil. E-mail: mffsobral@gmail.com

d. Doutor em Economia pela Universidade Federal de Pernambuco (UFPE). Docente do Programa de Pós-graduação em Administração e Desenvolvimento Rural na Universidade Federal Rural de Pernambuco (UFRPE), Recife, Pernambuco, Brasil. E-mail: andredesouzam@gmail.com 
represented the variable that most suffered impacts of the nominal exchange rate and international arrivals. The findings corroborate with other studies that say the tourist demand is affected by the exchange rate. However, the innovation of this article is to use domestic and international arrivals as variables to analyze the possible influence of the exchange rate on them.

Keywords: Nominal exchange rate; International tourist arrivals; Domestic tourist arrivals; Vectors autoregression.

\section{Resumen}

Análisis de la Relación Entre la Tasa de Cambio y los Desembarques Domésticos e Internacionales en Brasil

Este artículo se propone analizar, a través de un análisis econométrico, los efectos del tipo de cambio nominal sobre el número de desembarques nacionales e internacionales aéreos, en Brasil, en el período de 2001 a 2016. Como metodología, se utilizó el modelo de vectores autoregresivos. El análisis de los resultados demuestra que existe una relación de causalidad e influencia entre las variables. Se observó que el cambio influenció las demás variables, pero no fue influenciado por ellas. Además, el desembarque doméstico representó la variable que más sufrió impactos del tipo de cambio nominal y del desembarque internacional. Los hallazgos de la encuesta corroboran con otros trabajos que afirman que la demanda turística es afectada por el cambio. Sin embargo, la innovación de este artículo consistió en utilizar los desembarques tanto nacionales como internacionales como variables para analizar la posible interferencia del tipo de cambio en ellas.

Palabras clave: Tipo de cambionominal; Desembarques internacionales; Desembarques nacionales; Vectores autoregresivos.

\section{INTRODUÇÃO}

O Turismo é reconhecido hoje como uma das principais atividades econômicas do mundo, possuindo importância fundamental no desenvolvimento econômico de inúmeros países. Segundo o Ministério do Turismo (MTUR), quase 1,2 bilhão de pessoas viajaram para outros países no ano de 2015, representando um aumento de 4,6\% no fluxo de turistas internacionais em relação ao ano anterior (MTUR, 2016).

As Américas, no mesmo período receberam 192 milhões de turistas, tendo, a América do Sul, um crescimento de quase $6 \%$ na demanda de visitantes em relação a 2014 (MTUR, 2016). Esses resultados corroboram a ascensão da atividade turística a nível mundial, contribuindo para a geração de divisas, empregos e rendas.

0 turismo é considerado um fenômeno social que engloba qualquer pessoa, e qualquer local de destino, baseado na ocorrência de deslocamentos voluntários e temporários (Torre-Padilla, 1992). Alguns fatores, porém, podem influenciar o aumento ou diminuição das viagens como: taxa de câmbio, preços relativos ao turismo e a ocorrência de eventos inesperados (Cortés-Jimenez, Durbarry \& Pulina, 2009).

Ainda de acordo com o MTUR, a depreciação do real em relação a outras moedas fez com que os turistas brasileiros gastassem menos em viagens em 2015 (MTUR, 2016). Esse fato pode ser justificado através dos altos preços dos pacotes de viagens nacionais e internacionais, influenciados, também, pela alta do dólar. Em contrapartida, a valorização do dólar no Brasil pode-se apresentar como um 
incentivo para os turistas estrangeiros visitarem o país, já que seu poder de compra se torna maior em relação a moeda local.

Assim, fatores externos, como a variação cambial, podem afetar o número de viagens em uma localidade ou região, fato que pode ser analisado através da quantidade de desembarques nacionais e internacionais, em um determinado período de tempo. De acordo com Henry, Hyeongwoo \& Ka. (2013), o turismo é uma das atividades mais dependentes e sensíveis ao câmbio. Sua variação é capaz de determinar a escolha de destinos, meios de transportes e as despesas dos turistas em uma viagem. Como bem afirma Valença et al. (2015: 739): “a variação cambial influencia tanto os gastos dos turistas nacionais e estrangeiros quanto a tomada de decisão de destinos turísticos". Desta forma, percebe-se a importância do câmbio e sua necessidade de pesquisa também em outras esferas do Turismo, como a sua influência na demanda turística nacional e internacional, em um determinado país, por exemplo.

Diversos estudos buscaram identificar os principais fatores determinantes da demanda turística, dentre eles, as taxas de câmbio. Claveria e Torra (2014) utilizaram o modelo do Sistema de Demanda Ideal com o objetivo de quantificar a resposta da demanda turística francesa na Espanha, Itália, e Reino Unido às mudanças nas taxas de câmbio, preços dos produtos turísticos, orçamento dos turistas e eventos externos. Já Suresh, Bid \& Gunasekar (2015) identifica os fatores que influenciam a demanda turística receptiva nos estados indianos. Utilizando-se análises de dados de painel, seus resultados apontam que a taxa de alfabetização, número de operadores turísticos, existência de aeroportos e o índice de preços ao consumidor têm impactos significativos na determinação dos turistas estrangeiros para a região. Também com análise de dados de painel, Ekanayake, Halkides \& Ledgerwood (2012) investigaram o impacto de determinantes econômicos (preço dos produtos turísticos, renda do outro país, taxa de câmbio real, e custo da viagem) no aumento da demanda turística internacional nos Estados Unidos.

Neste sentido, esse estudo propõe-se analisar, através de um teste econométrico, os efeitos da taxa de câmbio sobre o número de desembarques nacionais e internacionais utilizando como meio de transporte o avião, no Brasil, no período de 2001 a 2016. Como metodologia foi utilizado o modelo Vetores Autorregressivos (VAR) buscando, dessa maneira, obter relações de causalidade entre as variáveis e suas consequências. 0 presente trabalho terá a seguinte estrutura, além dessa introdução, a próxima seção contém a revisão de literatura, seguida pela metodologia, análise dos resultados, e por fim as considerações finais.

\section{FUNDAMENTAÇÃo TEÓRICA}

Desde o século XIX, sobretudo com o desenvolvimento tecnológico dos transportes na época, são encontradas literaturas referentes à atividade turística (Barretto, 2000). Porém, só a partir da segunda guerra mundial foi desenvolvido o conhecimento do fenômeno do ponto de vista científico (Ruschmann, 1997). A relação turismo-transporte representa a função básica de aproximar o mercado receptor ao consumidor. Assim, o desenvolvimento econômico e social proporcionado pelo turismo tem uma dependência estreita com os transportes e seus aspectos de qualidade (Karassawa, 2003). 
A atividade turística, para muitos países, é tida como fator estratégico para alavancar o desempenho econômico (Lim, 1997). Essa abertura promove inúmeros benefícios internos como: maior grau de competição entre destinos, melhor alocação de recursos, rápida aquisição de inovação e conhecimento, além de níveis mais baixos de corrupção (Winters, 2006).

Para a OMT (2011), qualquer pessoa que saia do seu ambiente de residência fixa, em um prazo máximo de até um ano, realiza turismo. Essa definição independe de motivações de negócios, lazer ou outros. Por isso, é importante para os destinos identificar e quantificar essa demanda (previsão de chegada turística) no planejamento e na tomada de decisão de investimentos na atividade. A demanda turística pode ser medida pelo número de turistas - que se desloca de um local de origem para um determinado destino - realizando despesas diretas com a atividade (Chan \& $\mathrm{Li}$, 2008). Dessa forma, essa demanda pode ser quantificada como chegadas anuais, mensais ou até mesmo censo médio diário de visitantes (Sheldon, 1993).

De acordo com o Anuário Estatístico de Turismo (2016) do Ministério do Turismo, o modal aéreo foi responsável por aproximadamente $69 \%$ dos turistas que chegaram ao Brasil no ano de 2015. Ainda segundo essa pesquisa, o mês de janeiro concentrou o maior fluxo internacional de turistas ao Brasil, e juntamente com os meses de fevereiro, julho e dezembro compõem a alta temporada do turismo no país. Comprovando assim, a sazonalidade da atividade, uma das características que refletem o padrão dos fluxos turísticos atuais (Cortés-Jimenez et al., 2009).

No ano de 2014, devido a Copa do Mundo Fifa 2014, foram registrados fluxos superiores nos meses de junho e julho, comparado com os resultados dos anos anteriores (MTUR, 2015). Neste ano, a entrada de turistas foi superior a 6,4 milhões, sendo os principais emissores em ordem decrescente: Argentina, Estados Unidos e Chile (MTUR, 2015). Já em relação a demanda nacional, julho e dezembro representam os meses de maior concentração de viagens no Brasil, com 12,1\% e 18,8\%, respectivamente, ainda segundo pesquisas do Ministério do Turismo. 0 Nordeste e o Sudeste representam as regiões mais procuradas pelos turistas nacionais (MTUR, 2015).

Alguns fatores podem afetar a decisão de uma viagem, e consequentemente a demanda turística de um destino. Dentre esses, os: preços dos produtos turísticos; preços dos outros bens ou serviços ofertados; nível de renda dos turistas e os gostos pessoais dos mesmos (Lage \& Milone, 1991). Considerando-se que o turista compara produtos turísticos com preços parecidos, variáveis que estão relacionadas com o nível de atividade econômica (renda, câmbio, custos) são analisados, e podem determinar a demanda turística (Vanegas \& Croes, 2000). Como bem afirma Rahaby (2003) que definiu uma expressão de fluxo turístico pelos seguintes determinantes: renda da região emissora, taxa de câmbio entre os destinos (emissor e receptor), preços dos produtos turísticos da região receptora, preços das regiões alternativas (produtos substitutos) e fluxo turístico no tempo.

As taxas de câmbio apresentam elevada representatividade nos estudos sobre demanda turística utilizando-se modelos estatísticos. Essas, especificamente, podem gerar uma demanda para os centros receptores onde a moeda local está enfraquecida em relação à moeda do turista. Fato evidenciado por Vanegas \& Croes (2000), quando afirmam que essa variável é ainda mais relevante do que o nível de preços dos produtos turísticos na percepção dos turistas. 
Para Yap (2013), as taxas de câmbio podem influenciar a percepção de um viajante em relação à economia do outro país, e influenciar sua escolha entre um destino nacional ou internacional. Diante do exposto, poder-se-ia inferir, assim, a relação entre a depreciação da moeda brasileira com o aumento do número de entrada de turistas estrangeiros no Brasil. Por outro lado, a desvalorização do real impactaria no aumento das viagens nacionais, já que a moeda brasileira se encontraria enfraquecida ante outras moedas. É importante salientar, porém, que existem outros fatores aleatórios que podem interferir na demanda turística, como crises políticas, guerras e cataclismos (Mathieson \& Wall, 1982).

A crise econômica e financeira mundial de 2008 afetou a dinâmica da economia global, sobretudo dos produtos e serviços simulados pela cotação do dólar. Dentre esses exemplos podem ser citados os custos totais de viagens, alterados, sobretudo pelo preço do combustível, aluguel de aeronaves, dentre outros.

Lahmiri (2017) buscou analisar a existência da teoria do caos nos mercados de petróleo bruto antes e depois da crise internacional de 2008. Como resultados, constatou-se a presença de caos nesse período, ocasionando a volatilidade nos mercados dos tipos de petróleos analisados. Assim, fluxos de informações contraditórias e limitadas, condições desfavoráveis para produzir, movimentos aperiódicos dos preços e suas constantes flutuações são algumas das consequências relatadas. Desta maneira, essa recente crise não pode ser desconsiderada nos estudos relacionados a fluxos turísticos. Por isso, apesar do câmbio, nosso objeto de estudo, ser um fator essencial e avaliado pelos turistas, não representa por si só o fluxo de turistas de um destino.

Outro fator que pode interferir na demanda turística são os preços dos produtos turísticos da região receptora. Não existe um índice específico de preços do turismo, essa variável é medida através do índice de preços ao consumidor - como um indicador do custo de vida dos turistas (Witt \& Witt, 1995). Nesse contexto, um dos fatores determinantes das mudanças das quotas de destinos de um mercado de origem turística são os preços dos produtos turísticos (Claveria \& Torra, 2014). Seus resultados apontam sua relação efetiva às alterações desses preços como uma variável fundamental da demanda, juntamente com o orçamento de gastos dos turistas, taxas de câmbio e eventos externos (como grandes eventos esportivos, por exemplo). Essa relação de causa e efeito comprova a importância dos preços na competitividade do destino e no propósito da viagem (Dwyer, Forsyth \& Rao, 1999). Fato comprovado por Allen e Yap (2009) que através do seu estudo com abordagem de dados de painel concluíram que um aumento dos preços correntes do turismo levará uma queda de viagens domésticas em curto prazo na Austrália.

A renda configura-se como um importante determinante da demanda turística (Kusni, Kadir \& Nayan, 2013; Ekanayake et al., 2012). Como afirma Nelson, Dickey, e Smith (2011), que após estimarem um modelo de demanda de visitantes dos EUA para o Havaí, encontraram os seguintes fatores importantes: renda do estado de origem, tarifas (preços) e distância percorrida. Já em estudo realizado na Austrália (Allen e Yap, 2009), comprovaram que um aumento na renda familiar australiana ocasionará uma preferência por viagens internacionais ante as domésticas.

Pode-se avaliar o fluxo turístico de uma determinada região com diferentes ferramentas econométricas. Por exemplo, a relação entre o comércio internacional e as chegadas de turistas na América Latina (Lionetti \& Gonzalez, 2012). 0 estudo utiliza técnicas de cointegração e autorregressão de vetores, com o 
objetivo de testar a relação de curto / longo prazo entre turismo e comércio. A identificação de chegadas de países-fontes individuais é possível por meio da aplicação da técnica Análise de Espectro Singular (SSA), como realizada com os turistas que chegam aos Estados Unidos (Hassani h., 2015). Ademais, em estudo realizado na Austrália (Ma et al., 2016), foi possível conhecer através de um modelo de séries temporais SARIMA os padrões de chegadas dos turistas chineses. Esses resultados, no entanto, contribuem na prescrição de políticas e nas práticas de gestão turísticas australianas (Ma et al., 2016).

Deste modo, a demanda turística configura-se como um fator relevante a ser estudado, pois quanto mais turistas visitarem um país, mais negócios serão realizados e mais produtos e serviços nacionais e internacionais serão comercializados. Concomitantemente, a taxa de câmbio representa uma variável econômica capaz de influenciar a decisão de escolha dos turistas ante um destino a outro. Desse modo, esse estudo investigará até que ponto o câmbio, por si só, pode influenciar na atração de turistas internacionais e na ampliação do turismo doméstico em um país ou região.

\section{METODOLOGIA}

As variáveis utilizadas no estudo foram a taxa de câmbio nominal, e a quantidade de pessoas que desembarcaram de voos internacionais e domésticos ocorridos no Brasil entre 2001 e 2016. Os dados foram retirados respectivamente do Instituto de Pesquisas Aplicadas (IPEA) e do Ministério do Turismo (MTUR) (IPEADATA, 2017; MTUR, 2017). O Ministério do Turismo divulga através de relatórios anuais, pesquisas sobre a demanda turística nacional e internacional no Brasil. Para fins desse estudo, consideraremos como turistas os números totais desses desembarques, analisando seus resultados como demanda doméstica (voos internos) e demanda internacional (voos oriundos de outros países).

Definiu-se que seria usado o câmbio nominal, pois ele "representa os valores de uma moeda em relação às outras, sem a influência dos preços ou da inflação" (Valença et al., 2015: 746). E foi utilizado dados apenas de passageiros que utilizaram o avião como meio de transporte.

Foram utilizadas séries temporais das variáveis, que "são um conjunto de observações de valores que uma variável assume em diferentes momentos de tempo" (Gujarati \& Porter, 2011:11). As séries selecionadas são mensais e iniciam-se em janeiro de 2001 e vão até dezembro de 2016 totalizando 192 observações. Assim, foram estimados os vetores autorregressivos, com vistas a identificar a relação de casualidade entre o câmbio e os embarques e desembarques no Brasil. 0 modelo também permite através da decomposição de variância e a função impulso-resposta identificar a magnitude da causalidade entre as variáveis (Valença et al., 2015).

O modelo VAR, desenvolvido por Sims em 1980, foi escolhido como método porque é uma estrutura capaz de capturar a dinâmica em várias séries temporais, além de proporcionar uma abordagem coerente e confiável para a descrição de dados. É uma equação simples que é explicada pelos seus próprios valores defasados e pelos valores correntes e defasados das demais variáveis, eles capturam movimentos que não são detectados nos modelos uni ou bidimensionais (Stock e Watson, 2001). 
Para duas variáveis y e x o VAR assume a seguinte estrutura:

$$
\begin{aligned}
& Y_{t}=\beta_{10}+\beta_{11} Y_{t-1}+\cdots+\beta_{1 p} Y_{t-p}+Y_{11} X_{t-1}+\cdots Y_{1 p} X_{t-p}+u_{1 t} \\
& Y_{t}=\beta_{20}+\beta_{21} Y_{t-1}+\cdots+\beta_{2 p} Y_{t-p}+Y_{21} X_{t-1}+\cdots Y_{2 p} X_{t-p}+u_{2 t}
\end{aligned}
$$

Onde:

- $\beta_{s}$ e $Y_{s}=$ coeficientes desconhecidos

- $\mathrm{u}_{1 \mathrm{t}}$ e $\mathrm{u}_{2 \mathrm{t}}=$ ruídos brancos

O teste de causalidade de Granger propõe identificar a relação de causalidade entre as variáveis. Ele foi proposto por Granger em 1969 baseado na noção de precedência entre as variáveis. Isso quer dizer que,

se uma variável $\mathrm{Y}$ "causa" uma outra variável $\mathrm{X}$, a variável $\mathrm{Y}$ deve preceder a variável X e, portanto, deve ajudar a prever o valor desta variável Y. Se a previsão dos valores de $\mathrm{X}$ melhora ao incluir valor passados da variável Y, então se pode dizer que a variável X "causa no sentido de Granger" a variável Y. (Silva e Almeida, 2006: 9)

Ou seja, a variável independe Y, além de influenciar a variável dependente X, pode também ser influenciada por X. A relação de causalidade pode ocorrer nos dois sentidos, como também ser entre os valores passados da mesma variável ( $\mathrm{X}$ influencia X e Y influenciando Y). E há a possibilidade de que uma terceira variável (Z) estabeleça uma relação de causalidade com X e Y (Silva \& Almeida, 2006).

Para a aplicação dos métodos foi necessário inicialmente proceder com a dessazonalização das séries de desembarques, pois a atividade turística tem períodos de alta e baixa temporada. Em geral viaja-se mais durante janeiro, julho e dezembro, pois são os meses de férias escolares no Brasil. Ou seja, há "um comportamento cíclico" que ocorre com regularidade no calendário (Pindyck \& Rubinfeld, 2004). Portanto, para minimizar possíveis efeitos de sazonalidade incorreu-se nessa técnica.

Posteriormente, realizou-se um teste de raiz unitária, Teste de Dickey Fuller Aumentado (ADF), o teste KPSS e o teste de Phillip Perron para constatar a existência ou não de estacionariedade nas séries. De acordo com Stock e Watson (2004: 304) uma série temporal é estacionária "se a sua distribuição de probabilidade não muda ao longo do tempo". E a existência de não estacionariedade impacta na aplicação do VAR.

Adicionalmente, as séries foram submetidas ao teste de Granger para visualizar a existência de causalidade entre as variáveis. Para isto, o critério de escolha da defasagem do modelo foi o Schawartz (SBC), pois o número de observações era maiores de 100. Se fossem menores seria utilizado o critério de Akaike (AIC).

Constatou-se que a melhor defasagem era a primeira para o modelo. Essa defasagem também foi utilizada para estimar as funções impulso-resposta em choques nas variáveis e a decomposição de variância que revelam a intensidade da relação de causalidade. E assumiu-se que entre as variáveis a mais independente seria o câmbio, a mais dependente os desembarques domésticos e a menos dependente os desembarques internacionais. 
A escolha dos desembarques nacionais como a variável mais dependente deveu-se ao fato de que além dos mesmos serem influenciados pelos desembarques internacionais (em números de chegadas), são também pelo câmbio. Esse último justifica-se uma vez que vários custos de operações tais como combustível, aluguel, e manutenção das aeronaves são cotados em dólar (Nogueira \& Rosa, 2013). Custos esses que impactam diretamente nos preços dos bilhetes e consequentemente na quantidade de pessoas voando pelo país. Portanto há uma relação entre as variáveis do modelo autorregressivo corroborando com a afirmação de Melo \& Sampaio (2016).

Como variável exógena foi incluída uma dummy temporal representando a crise econômica mundial, entre outubro de 2008 e dezembro de 2009. Nesse período, de acordo com dados do Banco Mundial (2017), tanto o PIB brasileiro como o mundial sofreram quedas.

0 que se pretende é verificar como se dá essa relação tendo sempre em mente que há outras variáveis que não foram incluídas no modelo que podem influir nessa relação, tais como renda, atividade econômica, existência de produtos substitutos, concorrência entre as empresas, questões de preferência, motivações e outras possíveis questões psicológicas. De acordo com Meurer (2007) as variáveis que influem na demanda por viagens internacionais se separam em macroeconômicas, microeconômicas e fatores qualitativos. Essa classificação também pode ser utilizada para destinos domésticos.

\section{ANÁLISE dOS RESULTADOS}

Analisando os dados da tabela 1, considerando o nível de significância definido para que a hipótese nula seja rejeitada e exista causalidade entre as variáveis no teste de Granger foi de $5 \%$, se observa que há causalidade no sentido de Granger da variável câmbio para com ela mesma, mas não com as outras variáveis. Ou seja, as demais variáveis não causam a variável dita independente.

Tabela 1 - Teste de causalidade de Granger para a variável câmbio

\begin{tabular}{|l|c|c|}
\hline \multicolumn{1}{|c|}{ Variável } & F-Statistic & Significância \\
\hline Câmbio & 3297.1813 & 0.0000008 \\
\hline Desembarque internacional & 0.0026 & 0.9974435 \\
\hline Desembarque doméstico & 0.0000 & 0.9999811 \\
\hline
\end{tabular}

Fonte - elaboração própria.

Já a tabela 2, aplicando até os $5 \%$ como nível de significância, demostra que a variável desembarque internacional é impactada por ela mesma e pelo câmbio, mas não pelos desembarques nacionais. Evidenciando assim os achados de Suresh et al. (2015) Claveria e Torra (2014) e Ekanayake et al. (2012) que afirmam que a variação no câmbio/preço do turismo influencia a demanda turística internacional de um país ou região. Ademais, Meurer (2006), nos seus achados, encontrou que o número de viajantes internacionais no Brasil é sensível a taxa de câmbio, assim como o total de receitas obtidas pelo país. 
Tabela 2 - Teste de causalidade de Granger para a variável desembarque internacional

\begin{tabular}{|l|c|c|}
\hline \multicolumn{1}{|c|}{ Variável } & F-Statistic & Significância \\
\hline Câmbio & 3.7002 & 0.0265877 \\
\hline Desembarque Internacional & 605.9405 & 0.0000000 \\
\hline Desembarque Doméstico & 1.3600 & 0.2592351 \\
\hline & Fonte - elaboração própria. & \\
\hline
\end{tabular}

E os resultados do teste de Granger para a variável desembarque doméstico, tabela 3, evidencia que a relação é da variável com ela mesma. Todavia, considerando o nível de significância em 10\%, no sentindo de Granger o desembarque internacional também causa o desembarque doméstico.

Tabela 3 - Teste de causalidade de Granger para a variável desembarque doméstico

\begin{tabular}{|l|c|c|}
\hline \multicolumn{1}{|c|}{ Variável } & F-Statistic & Significância \\
\hline Câmbio & 1.8138 & 0.1659511 \\
\hline Desembarque internacional & 2.5708 & 0.0792336 \\
\hline Desembarque doméstico & 1042.6759 & 0.0000000 \\
\hline
\end{tabular}

Fonte - elaboração própria.

Na decomposição de variância da série câmbio, tabela 4, identifica-se que ela é quase na sua totalidade composta por ela mesma. As demais variáveis exercem pouca influência no seu comportamento dentro dos 40 períodos analisados. Ou seja, ao longo dos períodos os desembarques pouco influem no câmbio.

Tabela 4 - Decomposição de variância para a série câmbio

\begin{tabular}{|c|c|c|c|c|}
\hline Step & Std Error & Câmbio & $\begin{array}{c}\text { Desembarque } \\
\text { Internacional }\end{array}$ & $\begin{array}{c}\text { Desembarque } \\
\text { Doméstico }\end{array}$ \\
\hline 1 & 0.03649813 & 100.000 & 0.000 & 0.000 \\
\hline 10 & 0.16531259 & 99.994 & 0.006 & 0.000 \\
\hline 20 & 0.21038444 & 99.981 & 0.018 & 0.000 \\
\hline 30 & 0.23012108 & 99.961 & 0.036 & 0.003 \\
\hline 40 & 0.23960839 & 99.935 & 0.059 & 0.007 \\
\hline
\end{tabular}

No entanto, na composição do comportamento dos desembarques internacionais (tabela 5), há influência tanto do câmbio quanto dos desembarques domésticos. No caso do câmbio, corroborando com Meurer (2007) que afirma que o câmbio é uma das variáveis macroeconômicas explicativas para os desembarques internacionais e consequentemente para o estudo da demanda turística, sua influência é crescente nos 10 primeiros períodos, passando a ser decrescente. Diferentemente dos desembarques nacionais mantém uma influência crescente que chega até $11,48 \%$ no último período. Ou seja, enquanto no curto prazo é o câmbio que mais impacta nos desembarques internacionais, no longo são os desembarques nacionais que mais influenciam os internacionais. Fato corroborado por Massidda \& Etzo (2012) que encontraram que os destinos domésticos 
italianos competem entre si e com os destinos internacionais. Nesse sentido, explicam-se assim os achados no atual estudo sobre os desembarques nacionais influenciarem os internacionais, sendo ambos concorrentes.

Tabela 5 - Decomposição de variância para a série desembarques internacionais

\begin{tabular}{|c|c|c|c|c|}
\hline Step & Std Error & Câmbio & $\begin{array}{c}\text { Desembarque } \\
\text { Internacional }\end{array}$ & $\begin{array}{c}\text { Desembarque } \\
\text { Doméstico }\end{array}$ \\
\hline 1 & 0.04138266 & 0.005 & 99.995 & 0.000 \\
\hline 10 & 0.10046509 & 5.388 & 92.548 & 2.065 \\
\hline 20 & 0.13191227 & 4.539 & 89.864 & 5.597 \\
\hline 30 & 0.15518279 & 4.050 & 87.068 & 8.882 \\
\hline 40 & 0.17505202 & 3.954 & 84.557 & 11.489 \\
\hline \multicolumn{5}{|r|}{ Fonte - elaboração própria. } \\
\hline
\end{tabular}

Já o comportamento dos desembarques domésticos (tabela 6) é mais afetado pelos desembarques internacionais do que pelo câmbio, ambos de forma crescente. E no trigésimo período, o desembarque nacional já é mais afetado pelas duas outras variáveis $(19,93 \%$ pelo câmbio e $33,66 \%$ pelos desembarques internacionais) do que por ele mesmo (46,4\%). Allen e Yap (2009) confirma essa influência do câmbio, concluindo que quando ocorre um aumento dos preços correntes do turismo (passagens, por exemplo), ocasionará uma queda no número de viagens domésticas em curto prazo na Austrália. Também, por outra análise, Meurer (2012) concluiu que os turistas brasileiros podem efetuar substituições de destinos, na medida em que ocorrem alterações na taxa de câmbio real, das viagens domésticas para países diferentes.

Tabela 6 - Decomposição de variância para a série desembarques domésticos

\begin{tabular}{|c|c|c|c|c|}
\hline Step & Std Error & Câmbio & $\begin{array}{c}\text { Desembarque } \\
\text { Internacional }\end{array}$ & $\begin{array}{c}\text { Desembarque } \\
\text { Doméstico }\end{array}$ \\
\hline 1 & 0.03663338 & 0.646 & 6.415 & 92.940 \\
\hline 10 & 0.09992013 & 9.255 & 16.553 & 74.192 \\
\hline 20 & 0.14198234 & 16.542 & 26.753 & 56.705 \\
\hline 30 & 0.17579835 & 19.932 & 33.669 & 46.400 \\
\hline
\end{tabular}

Fonte - elaboração própria.

Os resultados das decomposições de variância comprovam a afirmação de Henry et al. (2013) de que a atividade turística é dependente e sensível a variações da taxa de câmbio. Ou seja, no caso deste estudo as variáveis desembarques internacionais e nacionais são dependentes da variação do câmbio. Corroborando com a afirmação de Yap (2013) de que o câmbio influencia a escolha dos destinos turísticos e consequentemente afeta os desembarques, sejam eles nacionais ou internacionais. Onde podemos analisar através da figura 1 e da tabela 7 o comportamento das variáveis desembarques, há um choque no câmbio. 0 efeito imediato nos desembarques internacionais é de queda brusca, inverso ao comportamento do câmbio, atingindo seu ponto máximo no mês quatro. E no caso dos desembarques nacionais há uma queda, todavia mais suave, com efeito máximo no vigésimo quinto mês após o choque. 
Figura 1 - Resposta de um choque no câmbio
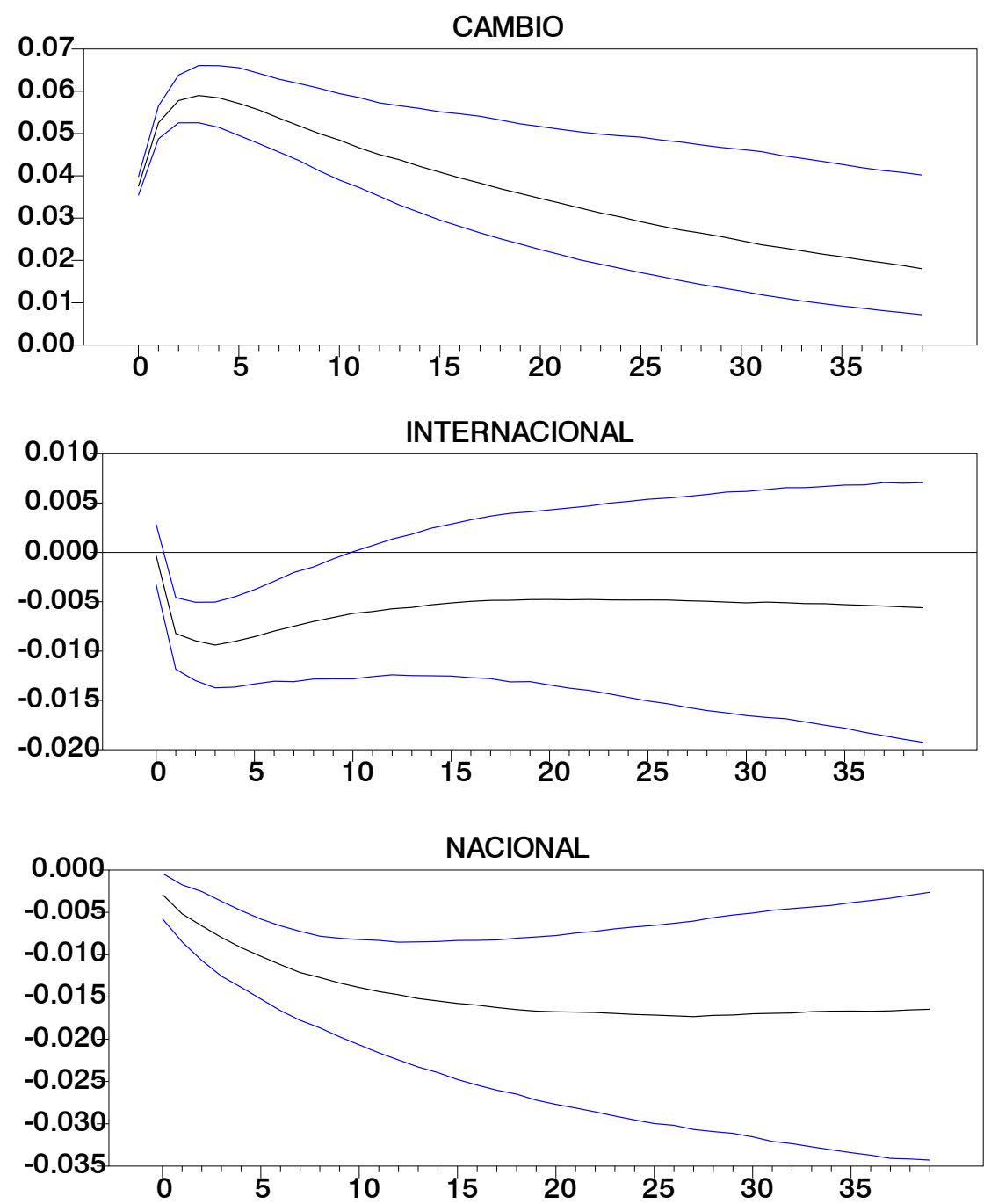

Tabela 7 - Respostas acumuladas (em valores relativos) das variáveis selecionadas a um choque de $1 \%$ no câmbio.

\begin{tabular}{|c|c|c|c|c|c|c|c|}
\hline \multicolumn{2}{|r|}{ Choque } & $\begin{array}{c}\text { Resposta } \\
\text { Máxima }\end{array}$ & $\begin{array}{c}\text { Resposta } \\
\text { Acumulada } \\
\text { Máxima }\end{array}$ & $\begin{array}{c}\text { Resposta } \\
\text { Acumulada } \\
\text { até o } 10^{\circ} \\
\text { período }\end{array}$ & $\begin{array}{c}\text { Resposta } \\
\text { Acumulada } \\
\text { até o 20ㅇ } \\
\text { período }\end{array}$ & $\begin{array}{c}\text { Resposta } \\
\text { Acumulada } \\
\text { até o } 30^{\circ} \\
\text { período }\end{array}$ & $\begin{array}{c}\text { Resposta } \\
\text { Acumulada } \\
\text { até o 40ㅇ } \\
\text { período }\end{array}$ \\
\hline \multirow[t]{2}{*}{ Câmbio } & $\begin{array}{l}\text { Desembarques } \\
\text { internacionais }\end{array}$ & 0,244248 & 5,774728 & 1,912652987 & 1,351947088 & 1,179425778 & 1,330702146 \\
\hline & $\begin{array}{l}\text { Desembarques } \\
\text { nacionais }\end{array}$ & 0,462336 & 15,79388 & 2,479805798 & 4,24739644 & 4,605226025 & 4,461451418 \\
\hline
\end{tabular}

Fonte - elaboração própria.

Porém, Albaladejo, González-Martínez \& Martínez-García (2016) propondo um modelo econométrico dinâmico para a demanda turística, concluiu que a variável preço relativo (o custo de vida dos turistas nos destinos em relação ao custo de vida no país de origem) não foi significativo para o seu modelo de turismo doméstico espanhol. Outras variáveis como o rendimento turístico per capita e o 
papel da persistência ou da reputação representaram os principais determinantes do turismo nacional e internacional da Espanha.

O Câmbio, como visto, é uma importante variável econômica capaz de influenciar a demanda turística de um destino (Henry et al., 2013; Yap, 2013) . Sua volatilidade atrelada, por exemplo, a fatores políticos, torna os preços dos principais produtos do turismo dependentes a sua variação (Vanegas \& Croes, 2000). Se a cotação do dólar aumenta no Brasil, consequentemente os preços das passagens aéreas nacionais e internacionais irão sofrer reajustes para cima, já que os combustíveis das aeronaves são cotados nessa moeda (Nogueira \& Rosa, 2013).

Entretanto, diferentemente do que deveria-se esperar nos resultados desse estudo, o câmbio não foi a variável mais determinante quando analisamos sua influência nos desembarques domésticos e internacionais. A influência do desembarque nacional foi mais forte nos desembarques internacionais e vice-versa quando comparados ao câmbio. Esse resultado está em acordo com Vanegas \& Croes (2000), que analisando fatores como a renda dos turistas, preço do turismo e o câmbio, esse último, no entanto, não foi o determinante mais importante na demanda turística internacional dos Estados Unidos para Aruba. Ademais, a importância desses fatores determinantes diferem de país para país (Vanegas \& Croes, 2000).

Assim, o turista ao escolher entre uma viagem nacional ou internacional automaticamente torna uma opção excludente da outra. Ou seja, são produtos substitutos, concorrentes entre si. Esse achado está em consonância com Meurer (2012: 267), quando afirma que "a oscilação do câmbio gera elevadas oscilações no número de viajantes brasileiros ao exterior". Essa interpretação é importante no sentido de que os governantes de um destino, assim como os profissionais diretos do turismo podem trabalhar mais eficazmente nos potenciais de desenvolver um produto doméstico, por exemplo, independente de fator preço. Abrindo, assim, margens de estudos sobre os fatores psicológicos e qualitativos ante meramente econômicos como determinantes da demanda turística.

\section{CONSIDERAÇÕES FINAIS}

0 turismo é considerado uma das principais indústrias do mundo. A atividade contribui em média com 5\% do PIB mundial, sendo responsável por gerar em torno de 6 a $7 \%$ do total de empregos global (Mihai e Simoni, 2012). Entretanto, essa atividade não é importante apenas por gerar grandes divisas internacionais, empregos e rendas, mas também por contribuir para a integração social, bem como possibilitar uma quebra das tensões provocadas pela rotina da vida moderna. Apesar do exposto, ainda são consideradas escassas as pesquisas sobre turismo, sobretudo, alinhadas a econometria.

A metodologia proposta na pesquisa fez uso de vetores autorregressivos para identificar a casualidade de Granger, a decomposição de variância e a função impulso-resposta entre o câmbio e os desembarques nacionais e internacionais no Brasil. A análise dos resultados demonstra que há uma relação de causalidade e influência entre as variáveis. Observou-se que o câmbio assumiu, nesse estudo, o papel de variável mais independente, pois ele influenciou as demais variáveis, mas não foi influenciado por elas. Além disso, o desembarque doméstico 
representou a variável que mais sofreu impactos da taxa de câmbio nominal e do desembarque internacional.

Essa pesquisa corrobora com achados de outros trabalhos que afirmam que a demanda turística é afetada pelo câmbio. No entanto, a inovação desse artigo consistiu em utilizar os desembarques tanto nacionais como internacionais como variáveis para analisar a possível interferência da taxa de câmbio nelas.

Como exposto, há outras variáveis macroeconômicas, microeconômicas e qualitativas que influenciam a demanda por turismo. Uma das limitações desse trabalho foi não utilizar outras variáveis no estudo. Todavia, esta lacuna identificada pode ser explorada em trabalhos posteriores como a construção de modelos que englobem outros fatores que influenciam a demanda turística, como: a renda per capita, a atividade econômica, dentre outros.

\section{REFERÊNCIAS}

Albaladejo, I., González-Martínez, M. I., \& Martínez-García, M. P. (2016). Nonconstant reputation effect in a dynamic tourism demand model for Spain. Tourism Management, 53, 132-139.

Allen, D. E., \& Yap, G. (2009). Modelling Australian domestic tourism demand: A panel data approach" Joondalup, Edith Cowan University, Australia.

Almeida, E. L. F., \& Silva, C. M. S. (2006). Formação de um mercado internacional de etanol e suas interrelações com os mercados de petróleo e açúcar. In XI Congresso Brasileiro de Energia, Rio de Janeiro, Brasil.

Banco Mundial. (2017). PIB Mundial. Referenciado em: http://datos.bancomundial.org/ indicator/NY.GDP.MKTP.CD?end=2015\&start=2006\&view=chart. Acesso 11 mar. 2017.

Barretto, M. (2000). Manual de iniciação ao estudo do turismo. Papirus, São Paulo.

Chan, K. C., \& Li, J. (2008). Audit committee and firm value: evidence on outside top executives as expert-independent directors. Corporate Governance: An International Review, 16(1), 16-31.

Cheng, K., Kim, H., \& Thompson, H. (2013). The real exchange rate and the balance of trade in US tourism. International Review of Economics \& Finance, 25, 122-128.

Claveria, O., \& Torra, S. (2014). Forecasting tourism demand to Catalonia: Neural networks vs. time series models. Economic Modelling, 36, 220-228.

Cortés-Jiménez, I., Durbarry, R., \& Pulina, M. (2009). Estimation of outbound Italian tourism demand: a monthly dynamic EC-LAIDS model. Tourism Economics, 15(3), 547-565.

Torre-Padilla, O. (1997). El turismo: fenómeno social. Fondo de Cultura Económica, México.

Dwyer, L., Forsyth, P., \& Rao, P. (1999). Tourism price competitiveness \& journey purpose. Turizam, 47(4), 283-299.

Ekanayake, E. M., Halkides, M., \& Ledgerwood, J. R. (2012). Inbound international tourism to The United States: A panel data analysis. International Journal of Management and Marketing Research, 5(3), 15-27.

Gujarati, D. N., \& Porter, D. C. (2011). Econometria Básica-5. AMGH Editora.

Hassani, H., Webster, A., Silva, E., \& Heravi, S. (2015). Forecasting US tourist arrivals using optimal singular spectrum analysis. Tourism Management, 46, 322-335.

Henry, T., Hyeongwoo, K.; Ka, C. M. (2013). The real exchange rate and the balance of trade in US tourism. International Review of Economics and Finance, 25, 122-128. 
IPEADATA. (2017). Instituto de Pesquisa Econômica Aplicada. Taxa de Câmbio. Referenciado em: http://ipeadata.gov.br/ExibeSerie.aspx?serid=38389. Acesso 12 mar. 2017.

Karassawa, N. (2003). Aspectos de qualidade da logística no turismo: estudo de caso. Dissertação de mestrado, Universidade Paulista, São Paulo, Brasil.

Kusni, A., Kadir, N., \& Nayan, S. (2013). International tourism demand in Malaysia by tourists from OECD countries: A panel data econometric analysis. Procedia Economics and Finance, 7, 28-34.

Lage, B. H. G., \& Milone, P. C. (2000). Economia do turismo. Atlas, São Paulo.

Lahmiri, S. (2017). A study on chaos in crude oil markets before and after 2008 international financial crisis. Physica A: Statistical Mechanics and its Applications, 466, 389-395.

Lim, C. (1997). Review of international tourism demand models. Annals of tourism research, 24(4), 835-849.

Lionetti, S., \& Gonzalez, O. (2012). On the relationship between tourism and growth in Latin America. Tourism and Hospitality Research, 12(1), 15-24.

Ma, E., Liu, Y., Li, J., \& Chen, S. (2016). Anticipating chinese tourists arrivals in Australia: A time series analysis. Tourism Management Perspectives, 17, 50-58.

Massidda, C., \& Etzo, I. (2012). The determinants of Italian domestic tourism: A panel data analysis. Tourism Management, 33(3), 603-610.

Mathieson, A., \& Wall, G. (1982). Tourism, economic, physical and social impacts. Longman Scientific and Technical, Harlow.

Melo, A. D. S., \& Sampaio, Y. D. S. B. (2016). Uma nota sobre o impacto do preço do açúcar, do etanol e da gasolina na produção do setor sucroalcooleiro. Revista Brasileira de Economia, 70(1), 61-69.

Meurer, R. (2006). 0 comportamento das receitas de viagens internacionais do Brasil: uma explicação macroeconômica. Revista Turismo em Análise, 17(3), 75-90.

Meurer, R. (2007). Comportamento das despesas com viagens internacionais do Brasil: 1947 a 2005. Turismo-Visão e Ação, 9(3), 359-374.

Meurer, R. (2012). Turismo emissivo brasileiro - Uma análise com modelos de dados em painel. Turismo-Visão e Ação, 14(2), 261-268.

Mihai, D., \& Simoni, S. (2012). Analysing the main indicators of global tourism flows in evolution and structure. Scientific Bulletin-Economic Sciences, 11(Special), 10-19.

MTUR. (2015). Dados e Fatos. Anuário Estatístico, 2015. Referenciado em: http://www. dadosefatos.turismo.gov.br/2016-02-04-11-53-05.html. Acesso 17 mar. 2017.

MTUR. (2016). Dados e Fatos. Anuário Estatístico, 2016. Referenciado em: http://www. dadosefatos.turismo.gov.br/2016-02-04-11-53-05.html. Acesso 17 mar. 2017.

MTUR. (2017). Dados e Fatos. Anuário Estatístico, 2017. Referenciado em: http://www. dadosefatos.turismo.gov.br/2016-02-04-11-53-05.html. Acesso 21 mar. 2017.

Nelson, L., Dickey, D., \& Smith, J. (2011). Estimating time series and cross section tourism demand models: Mainland United States to Hawaii data. Tourism Management, 32(1), 28-38.

Nogueira, D., \& Rosa, B. (2013). Com dólar alto, viajar de avião ficará mais caro. Referenciado em: https://oglobo.globo.com/economia/com-dolar-alto-viajar-de-aviao-ficara-maiscaro-8762228. Acesso 12 jun. 2017.

OMT. (2011). Destination Management: Conceptual Framework. Referenciado em: http://destination.unwto.org/content/conceptual-framework-0. Acesso 10 mar. 2017.

Pindyck, R. S., \& Rubinfeld, D. L. (2004). Econometria: modelos \& previsões. Elsevier, Rio de Janeiro.

Rabahy, W. A. (2003). Turismo e desenvolvimento. Editora Manole Ltda, Barueri. 
RATS. (2016). Introduction. Referenciado em: https://estima.com/ratsmain.shtml. Acesso 26 mar. 2017.

Sancho, A. (2001). Introdução ao turismo. Roca, São Paulo.

Sheldon, P. J. (1993). Forecasting tourism: expenditures versus arrivals. Journal of travel research, 32(1), 13-20.

Stock, J. H., \& Watson, M. W. (2001). Vector autoregressions. The Journal of Economic Perspectives, 15(4), 101-115.

Suresh, M., Bid, K., \& Gunasekar, S. (2015). Inbound international tourism development in India: A panel data analysis on its affecting factors. In Computational Intelligence and Computing Research (ICCIC), IEEE International Conference: 1-4.

Stock, J. H., \& Watson, M. W. (2004). Econometria. Addison Wesley, São Paulo.

Valença, M., Melo, A., Sobral, M., \& Xavier, M. (2015). Relação entre a taxa de câmbio e o setor de turismo: Análise por vetores autorregressivos. Turismo-Visão e Ação, 17(3), 737-757.

Ruschmann, D. (1997). Turismo e planejamento sustentável: A proteção do meio ambiente. Papirus editora, Campinas.

Vanegas Sr, M., \& Croes, R. R. (2000). Evaluation of demand: US tourists to Aruba. Annals of Tourism Research, 27(4), 946-963.

Winters, L. A. (2006). Will Trade Liberalisation Reduce Poverty? Trade Insight, 2(3), 14-17.

Witt, S. F., \& Witt, C. A. (1995). Forecasting tourism demand: A review of empirical research. International Journal of forecasting, 11(3), 447-475.

Yap, G. (2013). The impacts of exchange rates on Australia's domestic and outbound travel markets. Mathematics and computers in simulation, 93, 139-150.

Recebido em: $16 / 07 / 2018$

Aprovado em: 14/02/2019

\section{CONTRIBUIÇÕES}

Daniela de Moura Pavão Farias: Definição do problema de pesquisa e objetivos, desenvolvimento da proposição teórica, realização da revisão bibliográfica e fundamentação teórica, escolha dos procedimentos metodológicos, coleta e análise de dados, revisão crítica, redação e adequação do manuscrito às normas da RTA.

Lara Régia de Mélo Filho: Definição do problema de pesquisa e objetivos, desenvolvimento da proposição teórica, realização da revisão bibliográfica e fundamentação teórica, escolha dos procedimentos metodológicos, coleta e análise de dados, elaboração de tabelas, gráficos e figuras, realização de cálculos e projeções, redação do manuscrito e adequação às normas da RTA.

Marcos Felipe Falcão Sobral: Escolha dos procedimentos metodológicos, análise de dados, elaboração de tabelas, gráficos e figuras, realização de cálculos e projeções, revisão crítica e adequação do manuscrito às normas da RTA.

André de Souza Melo: Escolha dos procedimentos metodológicos, análise de dados, elaboração de tabelas, gráficos e figuras, realização de cálculos e projeções, revisão crítica e adequação do manuscrito às normas da RTA. 